\title{
O CHOQUE TEÓRICO DA POLITECNIA
}

\section{THE THEORECTICAL SHOCK OF THE POLYTECHNIC}

\author{
Dermeval Saviani 1
}

Resumo Este trabalho se originou do Seminário Choque Teórico, realizado no Rio de Janeiro de 2 a 4 de dezembro de 1987 e organizado pela Escola Politécnica de Saúde Joaquim Venâncio, da Fundação Oswaldo Cruz. Convidado a participar desse seminário para tratar da concepção de politecnia, fiz uma exposição oral, não baseada em texto escrito. A exposição foi gravada e transcrita, tendo sido publicada em livro (Saviani, 1989) acompanhada do debate que se lhe seguiu. As oito intervenções ocorridas no debate foram objeto de respostas relativamente longas em que tive oportunidade de explicitar melhor vários dos pontos abordados na apresentação do tema. A parte I deste artigo é constituída pela versão revista da exposição apresentada no referido seminário. A parte II retoma a discussão do conceito de politecnia, trazendo novos elementos para a compreensão de seu significado, em correlação com a situação histórica atual. Palavras-chave politecnia; educação profissional; formação de trabalhadores.

\begin{abstract}
This work originated at the Seminar 'Theoretical Shock' organised by the Polytechnic Health School Joaquim Venâncio of the Oswaldo Cruz Foundation from 2nd to $4^{\text {th }}$ December 1987, in Rio de Janeiro. Having been invited to take part in this seminar to deal with the conception of polytechnic, I made an oral presentation not based on a written text. At the time, the presentation, together with the ensuing discussions, were taped and transcribed and later published in a book (Saviani, 1989). The eight interventions that occurred during the debate were the object of relatively long answers in which I had the opportunity to express, in a clearer form, a few of the issues dealt with in the presentation. Part I of this article is a revised version of my presentation at the seminar. Part II returns to the discussion on the concept of polytechnic, bringing new elements that will contribute towards a better understanding of its meaning in correlation with the present historical situation.
\end{abstract}

Key words polytechnical education; professional education; workers' formation. 


\section{Sobre a concepção de politecnia}

Lendo o documento "Utopia em Construção", correspondente ao projeto de criação do Politécnico da Saúde Joaquim Venâncio2, que serviu de referencial ao Seminário Choque Teórico, chamou-me a atenção a proposta de instaurar uma atividade na perspectiva da politecnia. É uma experiência que pode trazer importantes subsídios para se repensar a direção do sistema de ensino no país. Isto traz alguns complicadores, pois trata-se de articular o presente com o futuro, formulando uma proposta no interior de um sistema de ensino cuja ordenação não corresponde exatamente ao espírito dessa proposta.

De qualquer forma, me parece que é esse o movimento do real. Temos de, a partir das condições disponíveis, encontrar os caminhos para a superação dos limites do existente. Isso vale para a organização de uma determinada instituição, como é o caso do Politécnico da Saúde, e também para a questão legal, a redefinição da política educacional e a reorganização do sistema de ensino em todo o país. Considero importante formular propostas e implantar, desde agora, medidas que apontem para uma nova situação, porque é à luz destas propostas e da experiência que se podem incorporar, à legislação geral do ensino no país, medidas mais consistentes e mais avançadas. É nesse quadro que vejo a experiência do Politécnico da Saúde. Claro que, enquanto ela se implantar a partir da legislação existente, terá de fazer alguns ajustes, levando em conta as normas em vigor. Mas, na medida em que avança, pode se constituir em um patamar para que a nova legislação já incorpore esses avanços e nos liberte das amarras que a atual nos impõe.

De início, talvez pudesse contribuir retomando a concepção básica de Politecnia. Considero fundamental que isto esteja suficientemente claro para que possamos tomar as medidas mais práticas relativas à organização curricular. A noção de Politecnia deriva, basicamente, da problemática do trabalho. Nosso ponto de referência é a noção de trabalho, o conceito e o fato do trabalho como princípio educativo geral. Toda a educação organizada se dá a partir do conceito e do fato do trabalho, portanto, do entendimento e da realidade do trabalho. E por quê?

Para responder a essa questão, podemos partir das noções gerais que costumamos encontrar nos enunciados relativos à educação: que a educação diz respeito ao homem, que o papel da educação é a formação do homem, e assim por diante. Na verdade, ficamos com esses enunciados em um plano muito genérico e abstrato porque, geralmente, não nos perguntamos: o que é o homem? Ora, o que define a existência humana, o que caracteriza a realidade humana é exatamente o trabalho. $\mathrm{O}$ homem se constitui como tal à medida que necessita produzir continuamente sua própria existência. É o que diferencia o homem dos animais: os animais têm sua existência garantida pela natureza e, por conseqüência, eles se adaptam à natureza. O homem tem 
de fazer o contrário: ele se constitui no momento em que necessita adaptar a natureza a si, não sendo mais suficiente adaptar-se à natureza. Ajustar a natureza às necessidades, às finalidades humanas, é o que se faz pelo trabalho. Trabalhar não é outra coisa senão agir sobre a natureza e transformá-la.

Essa ação transformadora sobre a natureza é guiada por objetivos. Este é outro elemento diferenciador da ação humana. Os animais também agem, também exercem uma atividade, mas essas atividades não são guiadas por objetivos. Eles não antecipam mentalmente o que vão fazer, mas o homem sim. No início do quinto capítulo do livro um de O Capital, Marx (1968), tratando do processo de trabalho em geral, distingue o pior dos arquitetos da mais hábil das abelhas pelo fato de o arquiteto antecipar mentalmente o que irá realizar, ao passo que a abelha realiza uma ação por instinto.

Se é o trabalho que constitui a realidade humana, e se a formação do homem está centrada no trabalho - isto é, no processo pelo qual o homem produz a sua existência -, é também o trabalho que define a existência histórica dos homens. Através desta atividade, o homem vai produzindo as condições de sua existência, transformando a natureza e criando, portanto, a cultura e um mundo humano. Esse mundo humano vai se ampliando progressivamente com o passar do tempo.

$\mathrm{Na}$ formação dos homens, deve-se considerar o grau atingido pelo desenvolvimento da humanidade. Conforme se modifica o modo de produção da existência humana, portanto o modo como o ser humano trabalha, mudam as formas pelas quais os homens existem. É possível detectar, ao longo da história, diferentes modos de produção da existência humana que passam pelo modo comunitário, o comunismo primitivo; o modo de produção asiático; o modo de produção antigo, ou escravista; o modo de produção feudal, com base no trabalho do servo que cultiva a terra, propriedade privada do senhor; e o modo de produção capitalista, em que os trabalhadores produzem com meios de produção que não são deles. Esses diferentes modos de produção revolucionam sucessivamente a forma como os homens existem. E a formação dos homens ao longo da História traz a determinação do modo como produzem a sua existência.

A realidade da escola tem de ser vista nesse quadro. A escola, originalmente, era algo restrito. Isso se devia ao fato de que as habilidades que desenvolve, nessas formas primitivas, se restringiam a pequenas parcelas da humanidade. Aliás, a própria origem etimológica da palavra escola - ligada ao ócio, ao lazer - está relacionada a essas condições sociais de produção da existência humana. Na Grécia, a escola era o local do ócio, o ginásio era o local onde se praticavam jogos, se fazia ginástica. Era uma sociedade que, em seu conjunto, se mantinha utilizando trabalho escravo. Nessas condições, as funções intelectuais e, portanto, também a escola, ficavam restritas a uma pequena parcela da sociedade. 
Na Idade Média, o trabalho propriamente produtivo, que sustentava o conjunto da sociedade, era o trabalho servil, o cultivo da terra. Esse também era um trabalho desenvolvido segundo técnicas simples e reiterativas e que, portanto, não requeriam diretamente a incorporação de conhecimentos sistemáticos. Quem se dedicava ao trabalho intelectual era a parcela dos intelectuais, fundamentalmente concentrada no clero. As escolas, naquele momento histórico, se restringiam a esta parcela e, por isso, eram chamadas Escolas Monacais.

A sociedade moderna, desenvolvida a partir do advento do capitalismo, revoluciona constantemente as técnicas de produção e incorpora os conhecimentos como força produtiva, convertendo a ciência, que é potência espiritual, em potência material através da indústria. Por confronto com a sociedade medieval, a sociedade moderna operou uma modificação, uma inversão. A sociedade medieval se baseava na propriedade da terra; a classe dominante eram os senhores feudais; o trabalho dominante era a agricultura; a forma de convivência entre os homens era de tipo rural. Assim, na Idade Média, o campo prevalecia sobre a cidade e a agricultura, sobre a indústria - que, no modo de produção feudal, limitava-se ao artesanato. Com as mudanças ocorridas a partir do século XV, inverte-se essa relação: o campo passa a se subordinar à cidade, e a agricultura, à indústria. Por estes motivos, a sociedade moderna tende a um processo de industrialização da agricultura e urbanização do campo. Ela tende a assumir crescentemente a forma urbanoindustrial, porque a agricultura na sociedade moderna tende a ser crescentemente mecanizada, ou seja, industrializada. Incorporam-se as técnicas de produção industrial na própria produção agrícola. E o interior, o campo, tende a se urbanizar: as relações sociais tendem a se centrar nas formas urbanas, que passam a predominar sobre as rurais.

Uma das características desse tipo de sociedade é a passagem do direito consuetudinário para o direito positivo. O direito positivo significa que a sociedade se organiza segundo normas formais estabelecidas por convenções, conforme se explicita nas teorias que a sociedade moderna foi produzindo com referência na noção de Contrato Social que, significativamente, é o título de uma das principais obras de Rousseau (1976). A sociedade organizada nesses moldes e distante das relações naturais, assume, de maneira mais visível, a forma histórica, adotando normas resultantes das próprias relações entre os homens. E o direito positivo, que compendia essas normas, assume a forma escrita.

Esse tipo de sociedade tem, pois, como pressuposto, como premissa necessária, a introdução de códigos de comunicação não naturais, não espontâneos. É a partir daí que se pode entender a exigência de generalização dos códigos escritos, trazendo consigo, por conseqüência, a necessidade da generalização da alfabetização. Sobre esse pressuposto também se coloca a ques- 
tão da universalização da escola que, estando referida ao trabalho intelectual, à cultura letrada, se constitui como via de acesso aos códigos escritos. Nas formas de sociedade anteriores, a escola podia ficar restrita àquela pequena parcela da sociedade que precisava desenvolver esse tipo de trabalho. A sociedade capitalista, cujo eixo passa a girar em torno da cidade, incorpora, na própria forma de organização, os códigos escritos, gerando a necessidade de que todos possam dominá-los. Decorre daí a proposta de universalização da escola e é sobre essa base que vão se estruturar os currículos escolares.

Pode-se, pois, dizer que o currículo escolar, desde a escola elementar, guia-se pelo princípio do trabalho como o processo através do qual o homem transforma a natureza. Os homens não transformam a natureza individualmente, isoladamente, mas relacionando-se entre si. Sabemos que o indivíduo é um produto histórico tardio, já que o homem se constitui inicialmente como ser gregário, como ser em relação com os outros. Ele só se individualiza no processo histórico e é somente na época moderna, na sociedade capitalista, que surge o indivíduo em contraposição à sociedade.

O homem transforma a natureza ao mesmo tempo em que se relaciona com os outros homens. Essa é a base do currículo da escola elementar. O currículo da escola elementar envolve o conhecimento da natureza porque se o homem, para existir, tem de adaptar a natureza a si, é preciso conhecê-la. Progressivamente, ele vai desenvolvendo formas de identificar como a natureza está constituída, como se comporta, ou, em outros termos, que leis regem a existência e a vida da natureza. Assim, as ciências naturais compõem um bloco do currículo da escola elementar.

Porém, uma vez que, ao produzir a sua existência transformando a natureza, os homens também travam relações entre si e estabelecem normas de convivência, surge a necessidade de se conhecer como os homens se relacionam entre si, quais as normas de convivência que estabelecem, ou seja, como as formas de sociedade se constituem. Surge, então, a necessidade de um outro bloco do currículo da escola elementar que se poderia denominar ciências sociais, em contraposição ao de ciências naturais. No currículo tradicional da escola elementar, o bloco das ciências sociais traduziu-se nas disciplinas história e geografia. A história trata de como os homens se desenvolveram ao longo do tempo e das formas de sociedade constituídas; a geografia, por sua vez, estuda a ocupação do espaço terrestre pelos homens e as formas como eles se distribuem nesse espaço.

Esses conhecimentos que compõem o currículo escolar são chamados de científicos, porque são obtidos por métodos, por processos sistemáticos. E não existe o sistemático, o elaborado, fora de registros escritos. O oral é espontâneo, é assistemático; o sistemático supõe registros escritos e, por isso, a linguagem da ciência se expressa por escrito. Nós não temos propriamente ciência oral. É claro que temos conhecimentos orais, uma sabedoria oral, 
mas não propriamente a ciência em função do seu caráter metódico; este envolve a exigência de confronto, de teste, resultando daí a exigência de que isso se faça por escrito. É por isso que, quando se faz a história da ciência, essa história começa com o período em que os códigos de comunicação escrita se sistematizam. Nos primeiros momentos, é uma história daqueles poucos que desenvolviam conhecimento sistemático, trabalho intelectual.

A ciência também diz respeito a uma parcela pequena da humanidade nas formas de sociedade anteriores. Na sociedade moderna é que a Ciência diz respeito ao conjunto da sociedade, porque ela se converte em potência material incorporada ao trabalho socialmente produtivo. O domínio da ciência diz respeito, também, ao conjunto da sociedade, razão pela qual o currículo da escola elementar pressupõe, além dos dois elementos enunciados, os instrumentos de expressão desses conhecimentos, ou seja, o domínio da linguagem escrita. Então, o currículo básico da escola elementar é composto pelo domínio da linguagem, da matemática, das ciências naturais e das ciências sociais.

Vê-se, portanto, que o princípio que orienta, que fundamenta este processo é o trabalho. No ensino fundamental, o trabalho aparece de forma implícita. Nesse nível, o trabalho orienta e determina o caráter do currículo escolar em função da incorporação dessas exigências na vida da sociedade. A escola elementar não precisa, então, fazer referência direta ao processo de trabalho, porque ela se constitui basicamente como um mecanismo, um instrumento, por meio do qual os integrantes da sociedade se apropriam daqueles elementos também instrumentais para a sua inserção efetiva na própria sociedade. Ou seja, aprender a ler, escrever e contar, além dos rudimentos das ciências naturais e das ciências sociais, constituem pré-requisitos para compreender o mundo em que se vive, inclusive para entender a própria incorporação, pelo trabalho, dos conhecimentos científicos no âmbito da vida e da sociedade.

À medida que o processo escolar se desenvolve, surge a exigência de explicitar os mecanismos que caracterizam o processo de trabalho. Entendo, pois, que o ensino médio deveria já se organizar na forma de uma explicitação da questão do trabalho. Nessa etapa, o trabalho já aparece não apenas como uma condição, como algo que ao constituir, ao determinar a forma da sociedade, determina, por conseqüência, também o modo como a escola se organiza, operando, pois, como um pressuposto de certa forma implícito. Agora, trata-se de explicitar o modo como o trabalho se desenvolve e está organizado na sociedade moderna. Aí é que entra, então, a questão da politecnia.

A noção de politecnia se encaminha na direção da superação da dicotomia entre trabalho manual e trabalho intelectual, entre instrução profissional e instrução geral. A sociedade moderna, que generaliza as exigências do conhecimento sistematizado, é marcada por uma contradição: como se trata 
de uma sociedade alicerçada na propriedade privada dos meios de produção, a maximização dos recursos produtivos do homem é acionada em benefício da parcela que detém a propriedade dos meios de produção, em detrimento da grande maioria, os trabalhadores, que possuem apenas sua força de trabalho. Na sociedade capitalista, a ciência é incorporada ao trabalho produtivo, convertendo-se em potência material. O conhecimento se converte em força produtiva e, portanto, em meio de produção. Assim, a contradição do capitalismo atravessa também a questão relativa ao conhecimento: se essa sociedade é baseada na propriedade privada dos meios de produção e se a ciência, como conhecimento, é um meio de produção, deveria ser propriedade privada da classe dominante.

No entanto, os trabalhadores não podem ser expropriados de forma absoluta dos conhecimentos, porque, sem conhecimento, eles não podem produzir e, se eles não trabalham, não acrescentam valor ao capital. Desse modo, a sociedade capitalista desenvolveu mecanismos através dos quais procura expropriar o conhecimento dos trabalhadores e sistematizar, elaborar esses conhecimentos, e devolvê-los na forma parcelada.

O taylorismo é a expressão mais típica do que foi assinalado. Taylor (1968) partiu do estudo de tempo e movimento, observando como os trabalhadores produziam os conhecimentos sobre o trabalho que realizavam. Os trabalhadores os acumulavam a partir da prática, da própria experiência. Sabemos que o capitalismo, quando se constituiu, serviu-se da habilidade dos trabalhadores desenvolvida a partir da Idade Média. Os artesãos com habilidade de produzir determinados objetos foram reunidos em um mesmo local e postos a trabalhar a serviço do capital, operando com os meios de produção dos capitalistas. Isto traduz aquilo que Marx chama de Cooperação Simples: juntos, eles produzem, de maneira mais eficiente, maior quantidade em um mesmo tempo.

Com muitos artesãos em um mesmo local, foi-se aprofundando a divisão do trabalho. Considerou-se que, se um trabalhador se especializa em uma parte do trabalho, vai produzir, no mesmo intervalo de tempo, muito mais do que se montasse todo o produto. Então, se 10 trabalhadores, em uma hora, por exemplo, produziam 10 mesas, na medida em que se especializam - um em produzir os pés, o outro o tampo da mesa, o outro as tábuas laterais etc. - vão produzir, naquilo em que se especializaram, digamos, 20, e não 10 . O resultado é que, neste intervalo de tempo, o conjunto deles produziu 20 mesas. Esse é o processo da divisão do trabalho, partindo da cooperação simples, que realiza a socialização do trabalho sobre a base da apropriação privada dos meios de produção. A partir desse processo, a divisão foi se aprofundando e o capitalismo foi introduzindo mecanismos especificamente capitalistas de produção que culminam com a introdução da maquinaria e o desenvolvimento da grande indústria. 
O taylorismo desempenhou um papel importante, já que a partir do estudo do tempo e movimento, foi possível detectar quais eram as tarefas simples que cada trabalhador tinha de desenvolver a fim de contribuir para a produção de determinados bens. Uma vez sistematizado, o conhecimento relativo ao conjunto passa a ser propriedade privada dos donos dos meios de produção, ou dos seus representantes, aqueles trabalhadores intelectuais que representam os donos dos processos produtivos. Eles têm o domínio da concepção do processo e a compreensão do conjunto. Esse mesmo conhecimento é devolvido aos trabalhadores, porém na forma parcelada. Assim, o trabalhador domina algum tipo de conhecimento, mas apenas aquele relativo à parcela do trabalho que lhe cabe realizar.

Isso também está ligado à questão da escola. Todos já ouviram falar naquela famosa frase atribuída a Adam Smith, que reconhecia ser necessária a instrução para os trabalhadores: "instrução para os trabalhadores sim, porém, em doses homeopáticas". Significa que os trabalhadores têm de dominar aquele mínimo de conhecimentos necessários para serem eficientes no processo produtivo, mas não devem ultrapassar este limite.

Nesse quadro é que se delineia a concepção de profissionalização, do ensino profissionalizante. Esta concepção capitalista burguesa tem como pressuposto a fragmentação do trabalho em especialidades autônomas. Formamse trabalhadores para executar com eficiência determinadas tarefas requeridas pelo mercado de trabalho. Tal concepção também vai implicar a divisão entre os que concebem e controlam o processo de trabalho e aqueles que o executam. O ensino profissional é destinado àqueles que devem executar, ao passo que o ensino científico-intelectual é destinado àqueles que devem conceber e controlar o processo.

A noção de politecnia contrapõe-se a essa idéia, postulando que o processo de trabalho desenvolva, em uma unidade indissolúvel, os aspectos manuais e intelectuais. Um pressuposto dessa concepção é que não existe trabalho manual puro e nem trabalho intelectual puro. Todo trabalho humano envolve a concomitância do exercício dos membros, das mãos, e do exercício mental, intelectual. Isso está na própria origem do entendimento da realidade humana como constituída pelo trabalho.

Se o homem se constitui a partir do momento em que age sobre a natureza, adaptando-a a si, ajustando-a às suas necessidades (e ajustar às necessidades significa plasmar a matéria, a realidade, segundo uma intenção, segundo um objetivo, que é antecipado mentalmente), então o exercício da função intelectual já está presente nos trabalhos manuais os mais rudimentares, os mais primitivos. A separação dessas funções é um produto histórico-social e não é absoluta, mas relativa.

Essas manifestações se separam por um processo formal, abstrato, em que os elementos dominantemente manuais se sistematizam como tarefa de 
um determinado grupo da sociedade, ao passo que os elementos dominantemente intelectuais se sistematizam como tarefa específica de um outro grupo da sociedade. Temos, então, o que conhecemos por trabalhadores manuais, por profissões manuais. A sistematização dessas tarefas manuais passa a definir de forma dominante essas profissões, mas não excluem a função intelectual.

O próprio fenômeno da aprendizagem evidencia isso: se o trabalhador pode aprender essas funções, exercer essas atividades, é porque aplica a sua inteligência no domínio desse processo. Inversamente, as funções e as profissões ditas intelectuais têm esse nome porque se organizam tendo como eixo de articulação as funções intelectuais. Mas também não se fazem sem o recurso à prática, à ação manual. É por isso que a ciência não se faz sem manipulação da realidade e não se pensa sem a base da ação. O que a idéia de politecnia tenta trazer é a compreensão desse fenômeno, a captação da contradição que marca a sociedade capitalista, e a direção de sua superação.

A união entre trabalho intelectual e trabalho manual só poderá se realizar com a socialização dos meios de produção, colocando todo o processo produtivo a serviço da coletividade, do conjunto da sociedade. Na medida em que o processo de trabalho, historicamente, liberta os homens do jugo da natureza, do trabalho braçal, transferindo-o progressivamente para as máquinas, não ocorre nada mais do que um desenvolvimento do próprio controle da natureza pelo homem. As máquinas não são outra coisa senão energia natural que o homem controla. Ao construir as máquinas, o homem usa a energia da natureza para vencer obstáculos que ele antes tinha de vencer com a energia dos próprios músculos, do próprio corpo.

Ao transferir para as máquinas grande parte do trabalho socialmente necessário, o homem libera tempo para o seu usufruto. O trabalho intelectual, ao mesmo tempo que resulta em um crescimento material - que, por sua vez, repercute no trabalho intelectual-, disponibiliza mais tempo para o ser humano.

No entanto, tal processo, na sociedade capitalista, é marcado por uma distorção: os frutos desse processo são apropriados privadamente, o que faz com que o usufruto de tempo livre só exista para uma pequena parcela da humanidade, ao passo que os trabalhadores, em que pese o crescimento da riqueza social, são lançados na necessidade de prosseguir em um processo de trabalho forçado. A superação desse tipo de sociedade é que viabiliza as condições para que todos possam dedicar-se, ao mesmo tempo, ao trabalho intelectual e ao trabalho manual. A idéia de politecnia se esboça nesse contexto, ou seja, a partir do desenvolvimento atingido pela humanidade no nível da sociedade moderna, da sociedade capitalista, já detectando a tendência do desenvolvimento para outro tipo de sociedade que corrija as distorções atuais. 
Politecnia, literalmente, significaria múltiplas técnicas, multiplicidade de técnicas, e daí o risco de se entender esse conceito como a totalidade das diferentes técnicas fragmentadas, autonomamente consideradas. A proposta de profissionalização do ensino de segundo grau da lei 5692/71 (Brasil, 1971), de uma certa forma, tendia a realizar um inventário das diferentes modalidades de trabalho, das diferentes habilitações, como a lei chama, ou das diferentes especialidades. A escola de segundo grau teria a tarefa de formar profissionais nas diferentes especialidades requeridas pelo mercado de trabalho. E é por isso que, no apêndice do parecer 45/72, listavam-se mais de uma centena de habilitações, e ainda ficava em aberto a possibilidade de se incluírem outras que tinham escapado à argúcia ou à capacidade inventariante dos conselheiros. Os conselhos estaduais também poderiam acrescentar outras habilitações consideradas necessárias nas regiões sob sua jurisdição. Caso se entendesse a questão nesses termos e se a politecnia fosse o conjunto da totalidade das técnicas disponíveis, haveria uma relação sempre incompleta, sempre sujeita a acréscimo.

A noção de politecnia não tem nada a ver com esse tipo de visão. Politecnia diz respeito ao domínio dos fundamentos científicos das diferentes técnicas que caracterizam o processo de trabalho produtivo moderno. Está relacionada aos fundamentos das diferentes modalidades de trabalho e tem como base determinados princípios, determinados fundamentos, que devem ser garantidos pela formação politécnica. Por quê? Supõe-se que, dominando esses fundamentos, esses princípios, o trabalhador está em condições de desenvolver as diferentes modalidades de trabalho, com a compreensão do seu caráter, da sua essência. Não se trata de um trabalhador adestrado para executar com perfeição determinada tarefa e que se encaixe no mercado de trabalho para desenvolver aquele tipo de habilidade. Diferentemente, trata-se de propiciar-lhe um desenvolvimento multilateral, um desenvolvimento que abarca todos os ângulos da prática produtiva na medida em que ele domina aqueles princípios que estão na base da organização da produção moderna.

Como a produção moderna se baseia na ciência, há que dominar os princípios científicos sobre os quais se funda a organização do trabalho moderno. Pistrak, em Fundamentos da escola do trabalho (1981), afirma que o trabalho com a madeira e com o metal tem um grande valor educativo, ao passo que o trabalho com couro não tem valor educativo algum. Com este exemplo, simplesmente ele está tentando indicar que o importante é o domínio dos princípios, dos fundamentos do trabalho moderno. Por que o trabalho com o couro não tem valor educativo? Porque o couro está ligado à forma de trabalho artesanal, própria da Idade Média, do modo de produção feudal. O capitalismo superou o trabalho artesanal, que só subsiste na nossa sociedade na forma folclórica, como uma curiosidade preservada em termos de um registro cultural, mas não como o modo de ser do trabalho produtivo social. 
O artesanato não tem condições de competir com a indústria moderna, que envolve a produção em escala, a incorporação de técnicas mais avançadas e, por isto, mais econômicas. Os custos da produção industrial são muito inferiores aos da artesanal. O trabalho com o couro iria propiciar o domínio daquela atividade limitada - saber manejar o couro, os instrumentos que transformam o couro em determinado tipo de objeto. Já a madeira e o metal, dizia Pistrak na década de 20, constituíam a matéria-prima não só da maioria dos objetos produzidos pela sociedade moderna, mas também das ferramentas com que são fabricados. Por este motivo, o autor afirmava que nenhuma fábrica moderna podia dispensar uma oficina com madeira e metal.

Se pensarmos assim, parece possível entender melhor o sentido da politecnia. Se se trata de organizar o segundo grau, o ensino médio, sobre a base da politecnia, não seria o caso de multiplicar as habilitações ao infinito para cobrir todas as formas de atividade na sociedade. Trata-se de organizar oficinas, processo de trabalho real, porque a politecnia supõe a articulação entre o trabalho manual e o intelectual. Isto será organizado de modo que se possibilite a assimilação não apenas teórica, mas também prática, dos princípios científicos que estão na base da organização moderna. A partir deste conceito, o aluno terá não apenas de compreender todos os princípios científicos que conhece e assimilou de maneira teórica desde o ensino fundamental - em suma, como a natureza e a sociedade estão constituídas -, mas também de ser capaz de aplicar o conhecimento de que dispõe.

Ainda segundo Pistrak, em uma oficina onde se trabalha com madeira e metal, os princípios da Física podem ser compreendidos não apenas no seu enunciado teórico, na sua fórmula, mas em como se aplicam na prática produtiva. Se o ensino médio se constitui sobre esta base e se esses princípios são absorvidos, assimilados, e se o educando que passa por essa formação adquire a compreensão não apenas teórica, mas também prática do modo como a ciência é produzida, e de como se incorpora à produção dos bens, ele compreende como a sociedade está constituída, qual a natureza do trabalho nessa sociedade e, portanto, qual o sentido das diferentes especialidades em que se divide o trabalho moderno.

Dessa forma, ele estará habilitado a desenvolver qualquer uma dessas atividades específicas por ter assimilado os seus fundamentos. As atividades específicas que ele venha a desenvolver passam a ser configuradas mais como uma espécie de divisão de tarefas em um processo de trabalho cujo domínio é coletivo. E esta divisão de tarefas não requer uma formação específica, porque, na maior parte dos casos, é adquirida em serviço.

Aí está também a base do porquê de o projeto de profissionalização do segundo grau da lei 5692/71 não ter dado certo: porque sequer correspondia à realidade atual. O empresariado, na verdade, não demandava um profissional com formação específica, mas sim uma pessoa com formação básica, a 
partir da qual pudesse rapidamente absorver a forma de realização do trabalho como organizado na empresa.

Ao se pensar um projeto como o Politécnico, a referência de realização desta proposta se encontra delimitada ao âmbito da saúde, mas me parece da maior importância que o sentido da politecnia não se perca em função desta restrição de ordem mais conjuntural. A idéia de politecnia envolve a articulação entre trabalho intelectual e trabalho manual, implicando uma formação que, a partir do próprio trabalho social, desenvolva a compreensão das bases da organização do trabalho na nossa sociedade e que, portanto, nos permite compreender o seu funcionamento. Ao se discutir o projeto de uma escola politécnica em saúde, é preciso perguntar sobre a existência de um trabalho social real, além dos aspectos ligados à articulação entre pesquisa e ensino, pesquisadores atuando em laboratório, colocando o aparato de pesquisa a serviço também de um projeto de ensino. Ora, a Fundação Oswaldo Cruz, mantenedora do Politécnico, tem também hospitais. Isso significa que presta um serviço de saúde real, efetivo, à população, preenchendo, pois, o requisito da existência de um trabalho social real. Atendida essa exigência da formação politécnica, torna-se possível formar profissionais não apenas teórica, mas também praticamente num processo em que se aprende praticando, mas, ao praticar, se compreendem, de forma cada vez mais aprofundada, os princípios científicos que estão direta e indiretamente na base desta forma de se organizar o trabalho na sociedade.

Parece-me que, a partir daí, se teria um ponto de referência, um eixo para a definição da questão curricular. Nesse âmbito, é importante considerar que é necessário ultrapassar certas concepções que, embora estejam na moda e pareçam muito progressistas, precisam ser submetidas à crítica. Uma delas é, por exemplo, a questão da interdisciplinaridade.

Em certos momentos, acreditava-se que, pela via da interdisciplinaridade se iria superar a fragmentação do conhecimento, mas é preciso ter presente que a noção de interdisciplinaridade pode conter o risco apenas de uma justaposição. A própria noção, de certa forma, envolve o pressuposto da fragmentação. Com efeito, parte-se do entendimento que os conhecimentos são fragmentados e cada um tem uma especialidade. Se reúno diferentes profissionais, supondo com isso superar o problema, já estou pressupondo uma perspectiva parcial do conhecimento, contendo a idéia do especialista e do não-especialista. Por exemplo, se se reúnem quatro professores sendo um da área de filosofia, outro da sociologia, o terceiro da área de biologia e o último da geografia para fazer um trabalho interdisciplinar e se uma questão em pauta é identificada como sendo de ordem filosófica, geralmente todos se voltam para o representante da área de filosofia. Ele é quem tem de dizer como o problema se esclarece porque é especialista na área; os outros não são especialistas. Quando o problema é relativo à Biologia, todos os demais se vol- 
tam para o biólogo, porque ele vai dizer como a questão se equaciona da perspectiva da Biologia. Então, as diferentes perspectivas continuam fragmentadas, autônomas, e apenas se justapõem no trato dessa ou daquela questão.

Qual a implicação do que foi exposto? Se, por exemplo, se pensa nesses termos o currículo num ensino que visa a assumir o caráter politécnico, tomam-se, digamos, as matérias básicas como as ciências naturais, sejam consideradas globalmente ou nas suas diferentes disciplinas - física, química, biologia, etc.. Faz-se o mesmo com as ciências sociais: história, geografia, sociologia, psicologia, etc. Diante desse quadro, chama-se um professor de geografia, um de história, um de física, um de química, um de biologia, de modo que cada um dê a sua contribuição para que a idéia de politecnia se realize. E como fica a questão da prática? Nesse caso, chama-se o técnico de laboratório ou o enfermeiro e ele põe sua experiência a serviço do novo educando. Por esse caminho, a idéia própria da politecnia não está sendo realizada. É até admissível que em certos contextos se aja assim, à medida que não se tenha condições para avançar mais.

No entanto, é importante ter claro que são duas coisas distintas, o que significa que não se pode tomar o exemplo mencionado como característico do sentido da politecnia. Se tomo o trabalho como a referência, e, portanto, a questão é entender como o trabalho está organizado hoje, a intervenção da história, da geografia, dos diferentes elementos considerados necessários, teria que se dar como aprofundamento da compreensão do objeto, ou seja, como se constitui o trabalho na sociedade moderna, quais são as suas características e por que ele assume estas características e não outras. E uma tarefa como essa não necessariamente seria desenvolvida pelos professores de cada uma das disciplinas incluídas no currículo. E, na hipótese de isto acontecer, esses profissionais teriam de se imbuir do sentido da politecnia e pensar globalmente a questão do trabalho, explicando historicamente, geograficamente, este mesmo fenômeno.

Se, digamos, o professor de história apenas desenvolve o currículo convencional - História Antiga, Medieval, Moderna, Contemporânea - com todas aquelas noções de certo modo abstratas, desvinculadas do objetivo específico do Politécnico da Saúde, esta contribuição da história resulta muito prejudicada. É imprescindível que a articulação com o objetivo da escola esteja presente em todos os componentes do currículo e cada um dos profissionais do Politécnico deve ter uma visão sintética desse processo e não apenas uma visão analítica. Se ele se restringe à visão analítica, tem a visão do todo, mas sem consciência das partes que o compõem; ele sabe que as partes interferem, mas não sabe como se articulam, como elas se conectam para constituir uma totalidade orgânica. A tarefa de estabelecer essa totalidade orgânica seria relegada ao próprio aluno, ou a um profissional destacado para isso. 
Sem levar em conta os requisitos indicados não chegaremos a ter o que está sendo chamado de um Politécnico da Saúde. Teremos apenas um curso de habilitação em saúde ou um curso que oferece diversas habilitações na área de saúde, apenas organizado de uma forma mais consistente, com uma qualidade mais adequada, em condições mais satisfatórias, diferentemente das condições da nossa rede pública de ensino - que forma profissionais em condições precárias, não tem laboratórios e o professor tem de suprir o laboratório utilizando figuras dos livros ou slides, não se configurando a instância da atuação prática profissional; forma profissionais de saúde, mas em escolas que não dispõem de hospital ou que dele dispõem de uma maneira muito precária, através de convênios em que a prática de estágio é feita pro for$m a$, ao passo que na Fiocruz ter-se-ia algo mais consistente, com condições satisfatórias. Mas, se é para ultrapassar a concepção vigente, para se realizar a proposta em termos de uma concepção de politecnia, parece importante não perder de vista os elementos que procurei explicitar.

\section{Revisitando a concepção de politecnia}

Passados 15 anos desde a realização do Seminário Choque Teórico, o que teria levado a recém-criada revista Trabalho, Educação e Saúde à decisão de iniciar suas atividades com a publicação desse texto?

A pergunta é pertinente, uma vez que, como se sabe, o conceito de "politecnia" integra a tradição socialista - que sofreu um profundo abalo com o desmoronamento das experiências denominadas "socialismo real", fenômeno ocorrido no final dos anos 80 e início dos 90 do século XX, portanto, logo após a produção e concomitantemente à primeira publicação desse trabalho. Tentando encaminhar a resposta à questão formulada, abordarei os aspectos relativos ao modo de inserção do conceito de politecnia na tradição socialista e ao grau de pertinência desse tema no contexto das transformações pelas quais passa a sociedade atual.

$\mathrm{Na}$ abordagem marxista, o conceito de politecnia implica a união entre escola e trabalho ou, mais especificamente, entre instrução intelectual e trabalho produtivo. Entretanto, após minuciosos estudos filológicos da obra de Marx, Manacorda conclui que a expressão "educação tecnológica" traduziria com mais precisão a concepção marxiana do que o termo "politecnia" ou "educação politécnica". Mostrando a contemporaneidade entre o texto das Instruções aos delegados do Primeiro Congresso da Associação Internacional dos Trabalhadores, escrito em 1866, e O Capital, Manacorda constata que, em ambos os textos, há uma substancial identidade na definição do ensino que é adjetivado de "tecnológico" tanto nas Instruções como n'O Capital, aparecendo o termo "politécnico" apenas nas Instruções (Manacorda, 1991, 
p.30). Contudo, para além da questão terminológica, isto é, independentemente da preferência pela denominação "educação tecnológica" ou "politecnia", é importante observar que, do ponto de vista conceitual, o que está em causa é um mesmo conteúdo. Trata-se da união entre formação intelectual e trabalho produtivo, que, no texto do Manifesto, aparece como "unificação da instrução com a produção material", nas Instruções, como "instrução politécnica que transmita os fundamentos científicos gerais de todos os processos de produção" e n' O Capital, como "instrução tecnológica, teórica e prática".

Compreendo as preocupações filológicas de Manacorda que o levaram a propor uma distinção sugerindo que o termo "politecnicismo" se refere à "disponibilidade para os diversos trabalhos e suas variações", ao passo que "tecnologia", implicando a unidade entre teoria e prática, destacaria a omnilateralidade que caracteriza o homem:

“O primeiro termo, ao propor uma preparação pluriprofissional, contrapõe-se à divisão do trabalho específica da fábrica moderna; o segundo, ao prever uma formação unificadamente teórica e prática, opõe-se à divisão originária entre trabalho intelectual e trabalho manual, que a fábrica moderna exacerba. O primeiro destaca a idéia da multiplicidade da atividade (a respeito da qual Marx havia falado de uma sociedade comunista na qual, por exemplo, os pintores seriam "homens que também pintam"); o segundo, a possibilidade de uma plena e total manifestação de si mesmo, independentemente das ocupações específicas da pessoa“ (Manacorda, op.cit, p. 32, grifo do autor).

Essas considerações são feitas a partir da observação de que Marx, n 'O Capital, se refere às "escolas politécnicas e agronômicas" e também às "escolas de ensino profissional" onde os filhos dos operários recebem algum ensino tecnológico e são iniciados no manejo prático dos diferentes instrumentos de produção (Marx, 1968, p.559). Assim, o autor reconhece a existência dessas escolas criadas pela própria burguesia, detectando, aí, um movimento contraditório que envolve a necessidade de se atender à exigência objetiva, imposta pela grande indústria, de substituir o indivíduo parcial pelo indivíduo completamente desenvolvido. E Manacorda entende, em conseqüência, que o adjetivo "politécnica" refere-se à escola doada pela burguesia aos operários, onde já se faz presente, de forma limitada, o conteúdo pedagógico da "educação tecnológica".

Sem desconsiderar a validade das distinções efetuadas por Manacorda, penso que, grosso modo, pode-se entender que, em Marx, as expressões "ensino tecnológico" e "ensino politécnico" podem ser consideradas sinônimos. Se, na época de Marx, o termo "tecnologia" ainda era pouco utilizado nos discursos econômicos e o era menos ainda nos discursos pedagógicos da bur- 
guesia, de lá para cá essa situação se modificou significativamente. Enquanto o termo "tecnologia" foi definitivamente apropriado pela concepção dominante, o termo "politecnia" sobreviveu apenas na denominação de algumas escolas ligadas à atividade produtiva, basicamente no ramo das engenharias.

Assim, a concepção de politecnia foi preservada na tradição socialista, sendo uma das maneiras de demarcar esta visão educativa em relação àquela correspondente à concepção burguesa dominante. Com efeito, pode-se ver que a primeira parte deste texto, ao esclarecer o sentido de politecnia, mantém-se fiel aos enunciados de Marx, incorporando os dois aspectos tratados por Manacorda sob os termos "politecnicismo" e "tecnologia".

Entendo, em conseqüência, que continua pertinente a utilização da expressão "educação politécnica" com as suas derivações "escola politécnica", "ensino politécnico", "instrução politécnica" etc., para nos referirmos a uma concepção de educação que busca, a partir do desenvolvimento do capitalismo e de sua crítica, superar a proposta burguesa de educação. E, a meu ver, essa denominação é preferível à "educação tecnológica", pois, hoje em dia, é esta última expressão que nos remete imediatamente à concepção burguesa. De fato, quem, ao ouvir alguém se posicionar em defesa de uma educação de caráter tecnológico, concluiria tratar-se de uma posição socialista? O inverso, contudo, não deixa de ter procedência: a defesa de uma educação politécnica tende, imediatamente, a ser identificada com uma posição socialista.

Mas, se do ponto de vista da terminologia, a politecnia resulta pertinente exatamente em razão de estar referida à concepção socialista de educação, cabe perguntar sobre sua pertinência do ponto de vista histórico, político e pedagógico no atual contexto marcado, de um lado, pelo desmoronamento da experiência denominada de "socialismo real" e, de outro, pelas transformações que se processam na base material da sociedade capitalista traduzidas naquilo que se convencionou chamar de "terceira revolução industrial".

Quanto ao primeiro aspecto, já tive oportunidade de me manifestar em algumas ocasiões, inclusive no calor dos acontecimentos, quando, entre 1989 e 1990, produzi o texto A educação pública na conjuntura atual, publicado em meu livro Educação e questões da atualidade (Saviani, 1991).

De forma sintética, entendo que a obra de Marx, que veio a ser chamada por Engels de "socialismo científico", foi construída para analisar e compreender a sociedade capitalista. Sua motivação era colocar nas mãos dos trabalhadores um instrumento de luta representado pela teoria. Em sua pesquisa, Marx se propôs a esclarecer as leis que regem o nascimento, a existência, o desenvolvimento e a substituição do capitalismo por outra forma social de mais alto nível. O socialismo é o nome desta nova forma social que se gesta no interior do próprio capitalismo a partir das contradições que lhe são próprias. 
Vê-se, pois, que Marx não estudou a sociedade socialista e, como cientista, nem poderia fazê-lo, pelo simples fato de que essa forma social ainda não estava e nem está, atualmente, constituída. Para Marx, essa nova forma de sociedade só se constituiria após o esgotamento pleno de todas as possibilidades contidas no próprio capitalismo. Impõe-se, pois, a conclusão: Marx foi um teórico do capitalismo e não do socialismo. À luz dessas considerações, encerro a apresentação do livro Educação e questões da atualidade com as seguintes palavras:

“Em suma, o desmoronamento dos regimes do Leste europeu, em lugar de significar a superação de Marx, constitui, ao contrário, um indicador de sua atualidade. Levando-se em conta que uma filosofia é viva e insuperável enquanto o momento histórico que ela representa não for superado, cabe concluir que se o socialismo tivesse triunfado é que se poderia colocar a questão da superação do marxismo, uma vez que, nesse caso, os problemas que surgiriam seriam de outra ordem. Mas, os fatos o mostram, ele não triunfou. O capitalismo continua sendo ainda a forma social predominante. Portanto, Marx continua sendo não apenas uma referência válida, mas a principal referência para compreendermos a situação atual" (Saviani, 1991, p. 14).

Segue-se, pois, que, com a queda dos regimes ditos comunistas, não faz mais sentido falar em problemas do socialismo em contraponto aos problemas do capitalismo. Todos os problemas que enfrentamos na situação atual são problemas do capitalismo. E precisam ser resolvidos, ou seja, superados. Ao mesmo tempo, comprova-se, a cada dia, que o capitalismo gera problemas que ele não é capaz de resolver - o que exige, de forma cada vez mais evidente, a sua transformação, repondo, agora de forma radical, a questão do socialismo. Com efeito, "socialismo" não é outra coisa senão a categoria conceitual por meio da qual a prática histórica e a teoria dessa prática expressam o significado da superação do capitalismo a partir do desenvolvimento de suas contradições internas.

Se do ponto de vista histórico continua em pauta, sob o aspecto político, a questão do socialismo como expressão da exigência de superação da ordem capitalista, ainda vigente, então, sob o aspecto pedagógico, mantémse também em pauta a questão da politecnia, já que é por meio dessa expressão que se pode reconhecer imediatamente a concepção de educação que busca, a partir da própria sociedade capitalista, superar a concepção burguesa de educação.

Finalmente, cabe uma referência ao outro aspecto da questão, ligado ao problema das transformações da base material.

Como assinala Manacorda em Il marxismo e l'educazione, estamos diante de uma problemática central no marxismo: o caminho da humanidade parte 
da genérica natureza humana originária, caracterizada por múltiplas ocupações, passa pela formação de uma capacidade produtiva específica provocada pela divisão natural do trabalho e chega à conquista de uma capacidade omnilateral baseada, agora, em uma divisão do trabalho voluntária e consciente, envolvendo uma variedade indefinida de ocupações produtivas em que ciência e trabalho coincidem. Está em causa, aí, a momentosa questão da passagem do reino da necessidade ao reino da liberdade:

“Sobre a base daquele reino da necessidade, lá onde cessa o trabalho voltado para uma finalidade externa, e para além da esfera da produção material propriamente dita, surge, de fato, para Marx, o verdadeiro reino da liberdade, vale dizer, o desenvolvimento das capacidades humanas como fim em si mesmo" (Manacorda, 1964, p. 15).

Ora, como assinalei em outro trabalho (Saviani, 1994), as transformações que vêm se processando na base material da sociedade capitalista desde os anos 70 do século XX, correntemente denominadas de "Terceira Revolução Industrial", "Revolução da Informática", "Revolução Microeletrônica" ou "Revolução da Automação", vêm promovendo a transferência não apenas das funções manuais para as máquinas, como ocorreu na Primeira Revolução Industrial, mas também as próprias funções intelectuais. Do mesmo modo que, com a Primeira Revolução Industrial, desapareceram as funções manuais particulares próprias do artesanato, dando origem ao trabalhador em geral, agora também as funções intelectuais específicas tendem a desaparecer, provocando a necessidade de elevação do patamar de qualificação geral. Assim, se naquele período esse processo converteu a escola na forma principal e dominante de educação, atualmente parece que estamos atingindo o limiar desse mesmo processo quando o próprio desenvolvimento da base produtiva coloca a necessidade de universalização de uma escola unitária que desenvolva ao máximo as potencialidades dos indivíduos (formação omnilateral), conduzindoos ao desabrochar pleno de suas faculdades intelectuais-espirituais. O processo de produção se automatiza; em outras palavras, se torna autônomo, autoregulável, liberando o homem para a esfera do não-trabalho. Generaliza-se, assim, o direito ao lazer, ao tempo livre, atingindo-se o "reino da liberdade".

Contudo, ao mesmo tempo que o desenvolvimento das forças produtivas materiais aponta na direção indicada, as relações sociais vigentes, baseadas na propriedade privada dos meios de produção, realizam o movimento contrário, conforme constatara Marx em sua análise do desenvolvimento histórico dos modos de produção da existência humana:

Na produção social da sua existência, os homens estabelecem relações determinadas, necessárias, independentes da sua vontade, relações de produção que corres- 
pondem a um determinado grau de desenvolvimento das forças produtivas materiais. (...) Em certo estádio de desenvolvimento, as forças produtivas materiais da sociedade entram em contradição com as relações de produção existentes ou, o que é a sua expressão jurídica, com as relações de propriedade no seio das quais se tinham movido até então. De formas de desenvolvimento das forças produtivas, estas relações transformam-se no seu entrave. Surge então uma época de revolução social (Marx, 1973, pp.28-29).

Assim, as relações sociais vigentes, ao dificultarem a generalização da produção calcada na ampla incorporação das tecnologias avançadas, impedem também a universalização da escola unitária, vale dizer, a formação omnilateral preconizada pela concepção de politecnia. Em última instância, essa tendência só poderá se viabilizar com a universalização do trabalho intelectual geral. Com efeito, se todo o trabalho passa a ser feito pelas máquinas, é preciso não esquecer que as máquinas, enquanto extensão dos braços e do cérebro humanos, são instrumentos por meio dos quais o homem realiza sua atividade vital para satisfazer suas necessidades existenciais. Portanto, o trabalhador propriamente dito continua sendo o homem. Seu trabalho, nessa nova situação, já que inclusive as operações intelectuais específicas terão sido transferidas para as máquinas, será um trabalho intelectual de caráter geral. E consistirá em comandar e controlar todo o complexo das suas próprias criaturas.

Estamos, pois, num contexto em que, como dizia Gramsci, trava-se uma luta entre o novo que quer nascer e o velho que não quer sair de cena. $O$ desenvolvimento material põe novas exigências no que se refere aos processos formativos, em geral, e à qualificação da força de trabalho, especificamente. E os próprios empresários tendem a se mostrar mais sensíveis a essa questão. Desejam eles capacitação geral, rapidez de raciocínio, grande potencial de incorporação de informações, adaptação mais ágil, capacidade de lidar com conceitos abstratos e assim por diante. Mas a realização plena dessas exigências esbarra nos limites postos pelas relações de produção baseadas na propriedade privada dos meios de produção. Sendo o saber um meio de produção, sua apropriação pelos trabalhadores contraria a lógica do capital segundo a qual os meios de produção são privativos dos capitalistas, da burguesia, do empresariado, cabendo ao trabalhador a propriedade apenas de sua própria força de trabalho. Por outro lado, se os trabalhadores não possuem algum tipo de saber, eles não podem produzir. Eis a contradição. Como resolvê-la?

O taylorismo associado ao fordismo foi uma forma de resolver essa questão no contexto da chamada "Segunda Revolução Industrial". Aí, como se explicitou no primeiro texto deste debate, se procedeu à objetivação e ao parcelamento do trabalho por meio da estratégia de expropriação dos sabe- 
res dos trabalhadores, sua elaboração e devolução na forma parcelada. No contexto atual, o fordismo cede espaço ao toyotismo, introduzindo-se a flexibilização do trabalho e a chamada "qualidade total". Em lugar da produção em série e economia de escala, passa-se a produzir segundo demandas determinadas, diversificando-se os processos produtivos que se dirigem a determinados nichos ou segmentos do mercado. Com efeito, o que se chama "qualidade total" pode ser compreendido a partir de dois vetores: o primeiro, de caráter externo, diz respeito aos clientes; nesse aspecto, qualidade total significa a satisfação total do consumidor, ou seja, adequar, o máximo possível, o produto às exigências da clientela à qual ele se destina. O segundo vetor, de caráter interno, se refere ao envolvimento do operário com o sucesso da empresa, procurando-se induzir o trabalhador a "vestir a camisa" da empresa, com o pleno convencimento de que seu sucesso resulta de e é concomitante com o sucesso da empresa; assim, a competição inter empresas se reproduz no interior de cada empresa entre os trabalhadores em busca do "máximo de qualidade", eufemismo da máxima produtividade, isto é, da tendência a elevar ao índice máximo possível a extração da mais-valia exacerbando a exploração da força de trabalho. O resultado desse processo para os trabalhadores, enquanto classe, é mais desemprego, mais exclusão.

No contexto descrito, reedita-se, obviamente em termos novos, o fenômeno que ocorreu por ocasião da Primeira Revolução Industrial, quando a introdução da maquinaria, de instrumento que poderia libertar os trabalhadores do trabalho pesado, se converteu em meio que maximizava a exploração dos trabalhadores. Assim, as máquinas apareciam como algozes dos operários, porque estes tinham que se ajustar ao ritmo feérico das máquinas, esgotando todas as suas energias. Isso levou os trabalhadores a se insurgir contra as máquinas e promover a sua destruição. Entretanto, esse resultado não se devia às máquinas enquanto tais, mas aos interesses a que elas serviam. Em outros termos, o que conduzia a esse resultado era o fato de que as máquinas eram propriedade privada dos capitalistas. Portanto, o inimigo do proletariado não eram as máquinas, mas os donos das máquinas.

Atualmente ocorre um processo semelhante. $\mathrm{O}$ advento das novas tecnologias acena com a possibilidade de libertação de praticamente todo tipo de trabalho material, ampliando sem precedentes a esfera do tempo livre e nos colocando, portanto, no limiar do "reino da liberdade". No entanto, assim como as máquinas mecânicas, também as máquinas eletrônicas são introduzidas no processo produtivo sob a forma de propriedade privada dos capitalistas. Nessa condição, cumprem o papel de aumentar as taxas de acumulação às custas da exploração da força de trabalho, aumentando igualmente os índices de miséria e exclusão.

Estamos, enfim, diante de uma situação em que, mais do nunca, se faz necessário resistir e lutar pela transformação da sociedade, de modo a supe- 
rar os entraves que caracterizam a atual ordem social, caminhando em direção a uma forma social em que os homens - todos os homens - possam se beneficiar do imenso desenvolvimento das forças produtivas que resultaram em inestimáveis conquistas, obtidas com muito sofrimento pelo conjunto da humanidade ao longo de sua existência. Evidentemente, no estágio histórico já atingido, esse movimento de transformação não pode mais ser deixado à mercê de uma evolução natural e espontânea. Necessita, ao contrário, ser organizado de forma voluntária e consciente, de modo a superar a atual divisão e desumanização do homem, seja ele considerado como indivíduo ou como classe.

E, por se tratar de um processo voluntário e consciente, não pode prescindir do concurso da educação. Eis como a proposta de educação politécnica, enquanto uma concepção educativa voltada explicitamente para a superação das divisões apontadas, resulta extremamente atual e pertinente no quadro das transformações que se processam na realidade em que vivemos. Faz, pois, todo sentido fortalecer projetos como o da Escola Politécnica da Saúde Joaquim Venâncio, estendendo essa experiência a outras modalidades de atuação educativa e multiplicando-a em todo o país.

\section{Notas}

1 Doutor em Filosofia da Educação pela PUC-São Paulo e pós-doutor pela Universita degli Studi de Bologna - Itália. Professor emérito da Faculdade de Educação da Universidade de Campinas e pesquisador do CNPq. <saviani@globo.com>

2 A hoje Escola Politécnica de Saúde Joaquim Venâncio se chamava, até 1989, Politécnico da Saúde Joaquim Venâncio, denominação mantida do texto original. 


\section{Referências}

BRASIL. 1971. Lei 5.692, de 11 de agosto de 1971, que "fixa diretrizes e bases para o ensino de 1o e 2 o graus e dá outras providências". Diário Oficial da União. Brasília, v.1, p. 6.377, de 12/08/71.

MANACORDA, Mario A. 1964. Il marxismo e l'educazione. Roma: Armando Armando. 1991. Marx e a pedagogia moderna. São Paulo: Cortez/Autores Associados.

MARX, Karl. 1968. O Capital. Rio de Janeiro: Civilização Brasileira.

_. 1973. Contribuição para a crítica da economia politica. Lisboa: Estampa.

PISTRAK, Moisei M. 1981. Fundamentos da escola do trabalho. São Paulo: Brasiliense.
ROUSSEAU, Jean J. 1976. Du Contrat Social. Paris (Mayenne): Aubier Montaigne.

SAVIANI, Dermeval. 1989. Sobre a concepção de politecnia. Rio de Janeiro: EPSJV/ Fiocruz.

1991. Educação e questões da atualidade. São Paulo: Cortez/Livros do Tatu. . 1994. “O trabalho como princípio educativo frente às novas tecnologias". In: FERRETTI, Celso J. et al. (orgs.) Novas tecnologias, trabalho e educação: um debate multidisciplinar. Petrópolis: Vozes. TAYLOR, Frederick W. 1968. Princípios de administração científica, trad. brasileira, 5a. ed. São Paulo: Atlas. 